Revista Perspectivas Online: Exatas \& Engenharias Anais do V Seminário P\&D PROVIC/PIBIC

II Encontro de Iniciação Científica CNPq

Vol. 10, n 29, Suplemento, 2020

\title{
Levantamento das Áreas de Preservação Permanente a jusante do rio Paraíba do Sul no município de Campos dos Goytacazes - RJ
}

\author{
Camille Pereira de Oliveira ${ }^{1}$, Jhonny Lacerda ${ }^{2}$, Ronaldo de Sousa Araújo ${ }^{3}$, Zélia Maria \\ Peixoto Chrispim 4 \\ (1) Aluna de Iniciação Científica do PIBIC/ISECENSA - Curso Engenharia Civil; (2) Aluno de Iniciação Científica do PIBIC/CNPq - Curso \\ Engenharia Civil; (3) Pesquisador Colaborador - Laboratório de Estudos Urbanos e Ambientais - LEUA - Curso de Arquitetura e Urbanismo; (4) \\ Pesquisador Orientador - Laboratório de Pesquisa em Gestão e Tecnologias na Construção Civil - GETECC - Curso de Engenharia Civil - Institutos \\ Superiores de Ensino do CENSA - ISECENSA, Rua Salvador Correa, 139, Centro, Campos dos Goytacazes, RJ, Brasil
}

Um assunto em pauta e de grande recorrência tem sido a capacidade de resiliência dos rios, visto que a água é retirada dos rios para abastecimento e devolvida após uso. Vale salientar que o ciclo da água pode ser afetado nesse processo, quando a quantidade de efluentes lançados, ultrapassa a capacidade de renovação da água. E nesse processo, podem-se destacar as matas ciliares, que têm um papel fundamental na função hidrológica, sendo elas responsáveis pela preservação da qualidade e da quantidade dos recursos hídricos. Atualmente a Lei 12.651/2012, conhecida como Novo Código Florestal, estabeleceu diretrizes relacionadas com as Áreas de Preservação Permanente (APPs). No artigo $3^{\circ}$, II, encontram-se previstas as suas funções ambientais, tais como: preservar os recursos hídricos, a estabilidade geológica e a biodiversidade, facilitar o fluxo de fauna e flora, proteger o solo e assegurar o bem estar de populações. Neste contexto, o presente estudo tem como objetivo analisar as Áreas de Preservação Permanente a jusante do Rio Paraíba do Sul na cidade de Campos dos Goytacazes - RJ. A metodologia utilizada consiste nas seguintes etapas: coleta de dados bibliográficos e documentais, como artigos, mapas, leis, normas, teses, dissertações, imagens de satélite; revisão sistemática; quantificação das APPs; elaboração de tabelas e gráficos; geração de mapa. Os resultados das análises apresentaram um distanciamento da quantidade de mata ciliar existentes nas margens a jusante do rio Paraíba do Sul no município de Campos dos Goytacazes (apenas 11,21\%) e a quantidade exigida pela lei federal. Neste cenário, é importante ressaltar a necessidade de reflorestamento das áreas desmatadas. Assim, pode-se concluir que a principal razão para a supressão de mata ciliar ao longo do rio Paraíba do Sul, a jusante da zona urbanizada da cidade Campos dos Goytacazes, aconteceu para o desenvolvimento de atividades agropecuárias, e para a construção de obras de infraestrutura.

Palavras-chave: Resiliência. Mata Ciliar. APP.

Instituição de Fomento: ISECENSA; CNPq. 